\title{
Obituary: James Reed Holton (1938-2004)
}

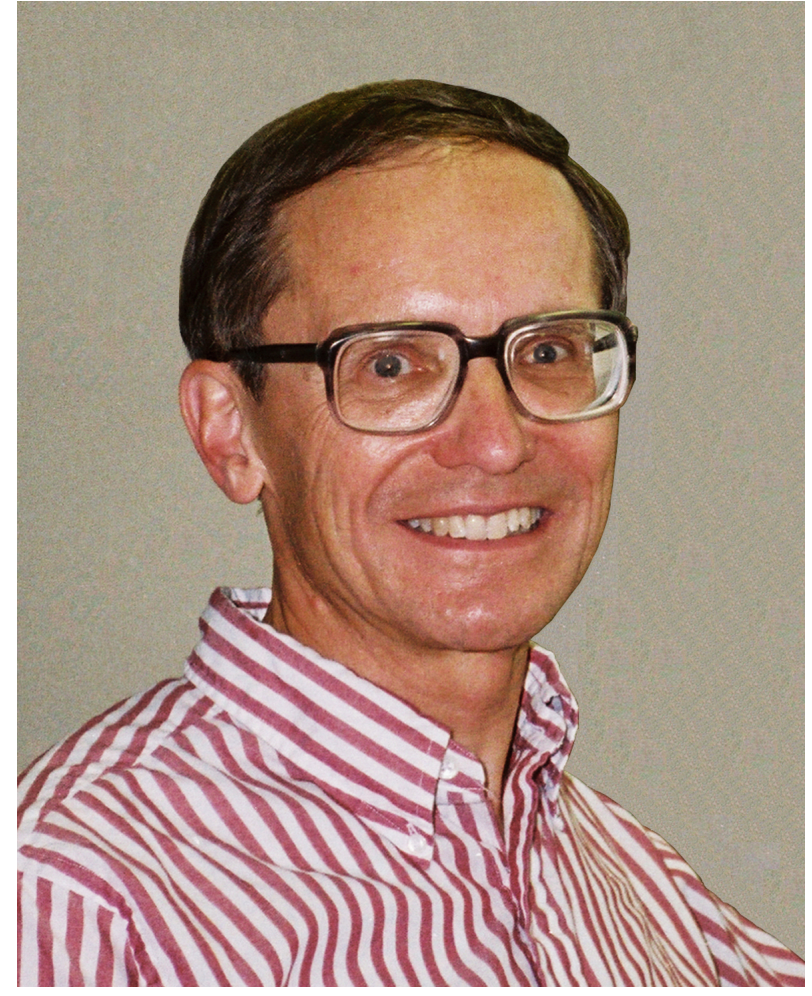

James R. Holton, 65, died on 3 March 2004 in University Hospital Seattle, Washington. Jim had suffered a stroke and heart attack while taking his mid-day run at Husky Stadium on 24 February 2004. He seemed in perfect health at the time. Holton had been a professor in the Department of Atmospheric Sciences at the University of Washington for 38 years. He was a highly respected teacher and researcher, the author of a leading textbook in dynamic meteorology, and a member of the advisory board of Atmospheric Chemistry and Physics.
Holton was born in Spokane, Washington and grew up in nearby Pullman, the site of Washington State University where his father studied diseases of wheat and was director of a USDA laboratory. He went to Harvard College, where he received a B.S. degree in physics in 1960. Jim worked with Professor Jule Charney at MIT and earned his Ph.D. in 1964.

He received an NSF postdoctoral fellowship that allowed him to enjoy a year in Stockholm, Sweden, where he visited the group of Bert Bolin. Holton took up his assistant professor position in the Department of Atmospheric Sciences at the University of Washington in 1965 and remained there, except for occasional sojourns around the world, until his death.

His first work had to do with studying fluid dynamics in the laboratory using rotating tanks of salt water. He studied the role of viscous boundary layers in transient flow situations, which led to an important paper on the nocturnal jet along the eastern slope of the Rockies. In 1968 he was author of four important papers on the Quasi-Biennial Oscillation of the tropical stratosphere, including a paper with R. $\mathrm{S}$. Lindzen, which is regarded as the essential explanation of the QBO.

The first edition of his textbook was published in 1972 . He received the Meisinger Award of the American Meteorological Society in 1973. Holton visited the Department of Applied Math and Theoretical Physics at Cambridge University in 1973-1974 and his AMS monograph on the dynamical meteorology of the stratosphere and mesosphere was published in 1975. This monograph marked the beginning of a long relationship with the community of researchers working on stratospheric dynamics, ozone and water vapor, and the interactions between the stratosphere and troposphere.

In 1982 he was awarded the Second Half Century Award of the AMS, which was later renamed the Charney Award. In 1983 he began working on the role of gravity waves in 
the stratosphere, and in 1984 wrote a review article on the water vapor puzzle of the stratosphere. In 1987 he published a co-authored book with David Andrews and Conway Leovy entitled "Middle Atmosphere Dynamics".

The themes of atmospheric dynamics, stratospheretroposphere constituent exchange, and gravity wave - mean flow interaction continued to benefit from Holton's insight and leadership for the remainder of his life. At the time of his death he was heavily engaged in planning for the Aura Satellite launch, the use of HIRDLS data, and various field programs designed to resolve questions relating to the role of the tropical tropopause transition layer in stratospheretroposphere exchange of energy and constituents. The fourth edition of "An Introduction to Dynamic Meteorology" appeared in 2004 and the six volume "Encyclopedia of Atmospheric Sciences", which he co-edited with Judy Curry and John Pyle, appeared in print in 2002.

Jim Holton was a brilliant lecturer, a well-loved teacher and an excellent mentor of young scientists. He leaves a tremendous legacy in the scientists he helped to develop. He supervised 26 doctoral students, and seven M. S. students. In addition, he worked with about 20 postdoctoral visitors at the University of Washington.
Holton won most of the awards available to an atmospheric scientist. In 1994 he was elected a member of the US National Academy of Sciences. He received an honorary doctorate from the Stockholm University and an honorary professorship from the University of Buenos Aires in 1998. He was awarded the Roger Revelle Medal of the AGU in 2000 and the Rossby Research Medal of the AMS in 2001 - the highest awards for excellence in research given by these two professional societies.

He served as Chairman of the Department of Atmospheric Sciences at the University of Washington from 1997-2002. He was an extremely generous colleague and was more than willing to contribute his time and resources to the benefit of his colleagues and the institutions he supported. At his memorial service, his colleagues, students and friends repeatedly testified to the kindness, generosity and humanity that accompanied both his scientific excellence and his athletic prowess.

Dennis L. Hartmann

Department of Atmospheric Sciences, Univ. of Washington, Seattle, WA, USA

(dennis@atmos.washington.edu) 